ARTICLE

\title{
A tailored multi-functional catalyst for ultra-efficient styrene production under a cyclic redox scheme
}

Xing Zhu1,2,4, Yunfei Gao ${ }^{1,4}$, Xijun Wang (10 1, Vasudev Haribal', Junchen Liu', Luke M. Neal', Zhenghong Bao ${ }^{3}$, Zili Wu (i) ${ }^{3}$, Hua Wang ${ }^{2} \&$ Fanxing Li (i) ${ }^{1 凶}$

Styrene is an important commodity chemical that is highly energy and $\mathrm{CO}_{2}$ intensive to produce. We report a redox oxidative dehydrogenation (redox-ODH) strategy to efficiently produce styrene. Facilitated by a multifunctional $(\mathrm{Ca} / \mathrm{Mn})_{1-x} \mathrm{O} @ \mathrm{KFeO}_{2}$ core-shell redox catalyst which acts as (i) a heterogeneous catalyst, (ii) an oxygen separation agent, and (iii) a selective hydrogen combustion material, redox-ODH auto-thermally converts ethylbenzene to styrene with up to $97 \%$ single-pass conversion and $>94 \%$ selectivity. This represents a $72 \%$ yield increase compared to commercial dehydrogenation on a relative basis, leading to $82 \%$ energy savings and $79 \% \mathrm{CO}_{2}$ emission reduction. The redox catalyst is composed of a catalytically active $\mathrm{KFeO}_{2}$ shell and a $(\mathrm{Ca} / \mathrm{Mn})_{1-x} \mathrm{O}$ core for reversible lattice oxygen storage and donation. The lattice oxygen donation from $(\mathrm{Ca} / \mathrm{Mn})_{1-x} \mathrm{O}$ sacrificially stabilizes $\mathrm{Fe}^{3+}$ in the shell to maintain high catalytic activity and coke resistance. From a practical standpoint, the redox catalyst exhibits excellent long-term performance under industrially compatible conditions.

\footnotetext{
${ }^{1}$ Department of Chemical and Biomolecular Engineering, North Carolina State University, Raleigh, NC, USA. ${ }^{2}$ State Key Laboratory of Complex Nonferrous Metal Resources Clean Utilization, Faculty of Metallurgical and Energy Engineering, Kunming University of Science and Technology, Kunming, China. ${ }^{3}$ Oak Ridge National Laboratory, Chemical Science Division and Center for Nanophase Materials Sciences, Oak Ridge, TN, USA. ${ }^{4}$ These authors contributed equally: Xing Zhu, Yunfei Gao. ${ }^{\circledR}$ email: fli5@ncsu.edu
} 
s an important chemical feedstock for rubber and plastics production, the global styrene production exceeded 31 million tons in 2018 and results in an annual $\mathrm{CO}_{2}$ emission of over 27 million tons ${ }^{1,2}$. At present, catalytic dehydrogenation $(\mathrm{DH})$ of ethylbenzene accounts for $\sim 90 \%$ of the styrene produced worldwide. This well-established approach suffers from high energy consumption, equilibrium-limited ethylbenzene conversion, and complex product separation, leading to significant $\mathrm{CO}_{2}$ emissions ${ }^{3,4}$. To compensate the heat required by the highly endothermic $\mathrm{DH}$ reaction, the industrial $\mathrm{DH}$ process uses significant amount of superheated steam as a heat source. At a typical dilution rate of $\sim 22: 1$ (steam:ethylbenzene by mole), co-injection of steam increases the equilibrium conversion while inhibiting coke formation and over-reduction of the potassium-promoted iron oxide $\mathrm{DH}$ catalyst ${ }^{5,6}$. Despite the large steam consumption that is highly energy-intensive, commercial $\mathrm{DH}$ process needs two reactors in series with interstage heating in order to achieve $64 \%$ ethylbenzene conversion ${ }^{7,8}$. The limited ethylbenzene conversion, coupled with by-products such as benzene and toluene, in turn complicates the product separation scheme. As such, transformative approaches to convert ethylbenzene to styrene with lowered energy conversion, higher single-pass yield, and simpler process scheme is highly desirable.

Oxidative $\mathrm{DH}(\mathrm{ODH})$ is a promising alternative to $\mathrm{DH}$, since simultaneous oxidation of hydrogen to water eliminates equilibrium limitations and leads to an exothermic overall reaction ${ }^{3,9}$. However, co-feeding gaseous oxygen in $\mathrm{ODH}$ often leads to undesirable carbon dioxide formation, lowering the selectivity to styrene. State-of-the-art ethylbenzene $\mathrm{O}_{2}-\mathrm{ODH}$ catalysts include high-surface-area activated carbon materials, carbon-doped boron nitride, and supported vanadium-based oxide. Styrene yields from these catalysts are typically limited to $60 \%$, with ethylbenzene feed partial pressure $<0.1 \mathrm{~atm}^{9-12}$. Moreover, the consumption of gaseous oxygen also increases the energy consumption, cost, and complexity of the process. Besides gaseous oxygen, carbon dioxide was also investigated as a soft oxidant for ethylbenzene $\mathrm{ODH}$, typical mechanisms include a modified Mars-van Krevelen-type redox mechanism, and a reverse watergas-shift reaction, which converts the $\mathrm{H}_{2}$ coproduct into water and $\mathrm{CO}^{13,14}$. Reported catalysts include $\mathrm{CeO}_{2}{ }^{13}$, activated carbon-supported $\mathrm{FeO}_{x}{ }^{15}$, and other mixed transition metal oxides ${ }^{16-19}$. Although $\mathrm{CO}_{2}-\mathrm{ODH}$ can facilitate $\mathrm{CO}_{2}$ utilization and enhance the equilibrium styrene yield, high carbon dioxide to ethylbenzene molar ratios $(\sim 10: 1)$ are necessary given the equilibrium-limited reverse water-gas-shift reaction ${ }^{16}$. The limited $\mathrm{CO}_{2}$ conversion would in turn increase the complexity and energy demand for the product separation steps. Moreover, $\mathrm{CO}_{2}-\mathrm{ODH}$ is more endothermic than conventional DH. As such, $\mathrm{CO}_{2}-\mathrm{ODH}$ processes are likely to be more energyintensive than the conventional $\mathrm{DH}$ route.

To address these challenges, we propose a redox-ODH scheme to efficiently convert ethylbenzene to styrene using a tailored multifunctional redox catalyst, which acts as a heterogeneous catalyst, an oxygen separation agent, and a selective oxidation material (Fig. 1a). Facilitated by the redox catalyst, redox$\mathrm{ODH}$ follows a chemical-looping-based approach, which has been previously reported for $\mathrm{CO}_{2}$ capture from fossil fuel combustion $^{20-22}$, methane-selective oxidation ${ }^{23-29}$, thermochemical water $/ \mathrm{CO}_{2}$ splitting ${ }^{30-37}$, air separation ${ }^{38-40}$, and $\mathrm{ODH}$ of light alkanes $^{41-43}$. To our knowledge, previous chemical-looping studies have yet to investigate catalytic conversion to hydrocarbon molecules containing more than four carbon atoms, mainly due to the high operating temperature required by conventional redox catalysts and/or lack of product selectivity 44,45 . In comparison, redox-ODH converts ethylbenzene at relatively low temperatures in two steps, with integrated air separation: in the ODH step, ethylbenzene is catalytically converted into styrene and water, where the active lattice oxygen in the redox catalyst assists ethylbenzene activation and selective hydrogen combustion (SHC). In the subsequent oxidation step, the lattice oxygen in the redox catalyst is replenished via reactive air separation. Resulted from effective SHC by the redox catalyst, the conversion of ethylbenzene to styrene becomes autothermal and is no longer limited by the thermodynamic equilibrium, achieving high single-pass styrene yield while simplifying the downstream product separation. Moreover, the in situ air separation facilitated by the redox catalyst renders a much safer and more efficient ODH scheme ${ }^{44}$. Figure $1 \mathrm{~b}$ compares redox-ODH with conventional and emerging styrene production approaches. As can be seen, significant advantages can be anticipated resulting from the multifunctional redox catalyst and the unique redoxODH scheme. In the following sections, the performance of the multifunctional redox catalyst is first presented. This is followed with detailed characterization and density functional theory (DFT) calculations to reveal the underlying reaction mechanism and redox catalyst design and optimization strategy. Finally, the performance of the redox-ODH scheme is simulated with detailed ASPEN Plus simulations. Specifically, the redox catalyst reported in this study demonstrated $72 \%$ increase in single-pass styrene yield on a relative basis. The significantly intensified redox-ODH scheme has the potential to reduce energy consumption by $>80 \%$ when compared to the commercial DH process.

\section{Results}

Redox-ODH performance of ethylbenzene to styrene. This section reports the performance of the $(\mathrm{Ca} / \mathrm{Mn})_{1-x} \mathrm{O} @ \mathrm{KFeO}_{2}$ redox catalyst for redox-ODH of ethylbenzene. Details related to catalyst preparation and experimental setup are provided in the "Methods" section in the supplementary document (see Supplementary Fig. 1). As shown in Fig. 2a, redox-ODH on fully oxidized $(\mathrm{Ca} / \mathrm{Mn})_{1-x} \mathrm{O} @ \mathrm{KFeO}_{2}$ can be divided into two regions. Region 1 exhibited high $\mathrm{CO}_{2}$ selectivity (29.1\%), whereas region 2 exhibited $94.6 \%$ styrene selectivity with merely $0.1 \%$ selectivity towards $\mathrm{CO}_{2}$. A partial reoxidation with air can tune the degree of oxidation for the $(\mathrm{Ca} / \mathrm{Mn})_{1-x} \mathrm{O} @ \mathrm{KFeO}_{2}$ redox catalyst to take the advantage of the highly selective region 2 . As can been seen in Fig. 2b, the nonselective region 1 was near completely eliminated and $(\mathrm{Ca} / \mathrm{Mn})_{1-x} \mathrm{O} @ \mathrm{KFeO}_{2}$ exhibited excellent ethylbenzene conversion (97\%) and styrene selectivity (94.2\%) throughout the $\mathrm{ODH}$ step. Figure $2 \mathrm{c}$ summarizes the redox-ODH performance of $(\mathrm{Ca} / \mathrm{Mn})_{1-x} \mathrm{O} @ \mathrm{KFeO}_{2}$ as a function of ethylbenzene partial pressure. We note that commercial ethylbenzene $\mathrm{DH}(\mathrm{DH})$ process typically operates in a two-stage reactor with interstage reheating and at steam to ethylbenzene molar ratio of $\sim 22: 1^{8}$. The ethylbenzene partial pressure entering the secondary stage of the commercial reactor is around $0.1 \mathrm{~atm}$. At this partial pressure, the single-pass ethylbenzene conversion is thermodynamically limited to $73 \%$ at $600{ }^{\circ} \mathrm{C}$, whereas the actual plant performance gives rise to $64 \%$ ethylbenzene conversion with $83 \%$ selectivity towards styrene (53.1\% single-pass yield). In comparison, redox-ODH is not subjected to this equilibrium limitation since in situ combustion of the $\mathrm{H}_{2}$ by-product with $(\mathrm{Ca} / \mathrm{Mn})_{1-{ }_{x}} \mathrm{O} @ \mathrm{KFeO}_{2}$ leads to a thermodynamically favored, exothermic process. As can be seen in Fig. 2c, near 100\% conversion of ethylbenzene can be achieved throughout the partial pressure ranges we investigated (up to $0.1 \mathrm{~atm}$ ). More importantly, styrene selectivity maintained at a high level (94\%) with $0.1 \mathrm{~atm}$ (industrially comparable) ethylbenzene feed (balance Ar). The experimentally demonstrated redox-ODH yield at $0.1 \mathrm{~atm}$ ethylbenzene was $18 \%$ higher 
(a)

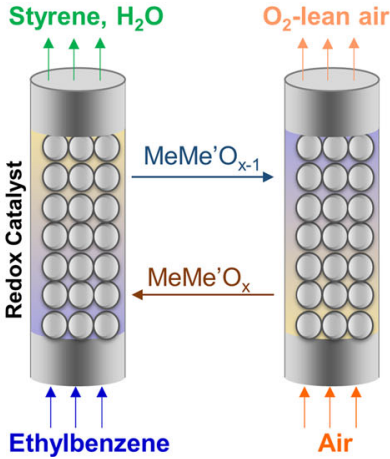

(b)

\begin{tabular}{|c|c|c|c|c|c|}
\hline Technology & $\begin{array}{l}\text { Equilibrium } \\
\text { Limited }\end{array}$ & $\begin{array}{c}\text { Dilution } \\
\left(\text { Steam or } \mathrm{CO}_{2}\right)\end{array}$ & $\begin{array}{l}\text { Heat of } 1 \\
\quad(\mathrm{~kJ} / \mathrm{I}\end{array}$ & $\begin{array}{l}\text { Reaction } \\
\text { nol) }\end{array}$ & $\begin{array}{l}\text { Separation } \\
\text { Load }\end{array}$ \\
\hline$D H$ & Y & Y & & 124.9 & High \\
\hline $\mathrm{O}_{2}-\mathrm{ODH}$ & $\mathrm{N}$ & Y & -121.9 & & \\
\hline $\mathrm{CO}_{2}-\mathrm{ODH}$ & Y & $Y$ & & 161.8 & Very high \\
\hline Redox-ODH & $\mathrm{N}$ & N & -121.9 & & w \\
\hline
\end{tabular}

Fig. 1 Schematic and the advantages of redox-ODH. a Schematic illustration of redox-ODH of ethylbenzene. $\mathrm{MeMe}^{\prime} \mathrm{O}_{x}$ represents a generic redox catalyst. b A comparison between ethylbenzene $\mathrm{DH}, \mathrm{O}_{2}-\mathrm{ODH}, \mathrm{CO}_{2}-\mathrm{ODH}$, and redox-ODH. Green background stands for desirable features. asteam dilution is necessary to avoid combustion limit. ${ }^{b} \mathrm{CO}_{2}-\mathrm{ODH}$ is still equilibrium limited compared to $\mathrm{O}_{2}$ - and redox-ODH due to the equilibrium limitation in R-WGS (reverse water-gas-shift).

(a)

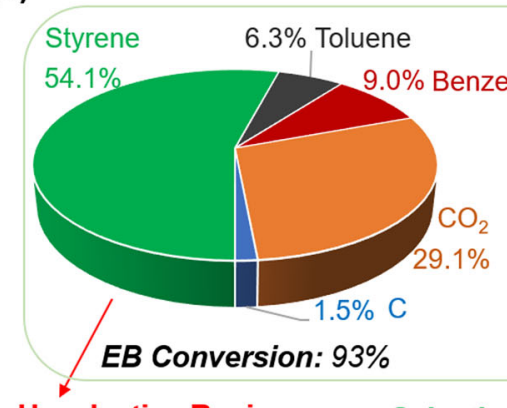

Redox-ODH with full re-oxidation

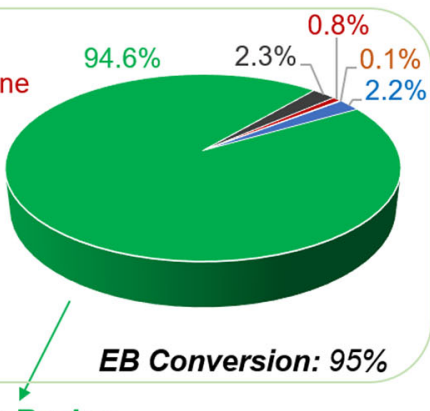

EB Conversion: $95 \%$
Unselective Region Selective Region

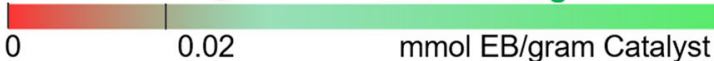

(b) Redox-ODH with partial re-oxidation

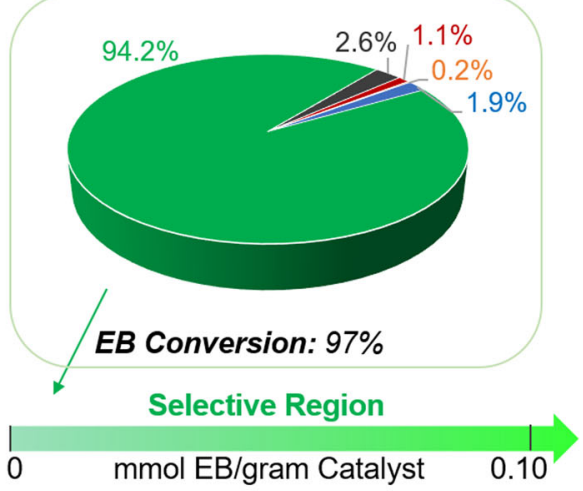

(c)

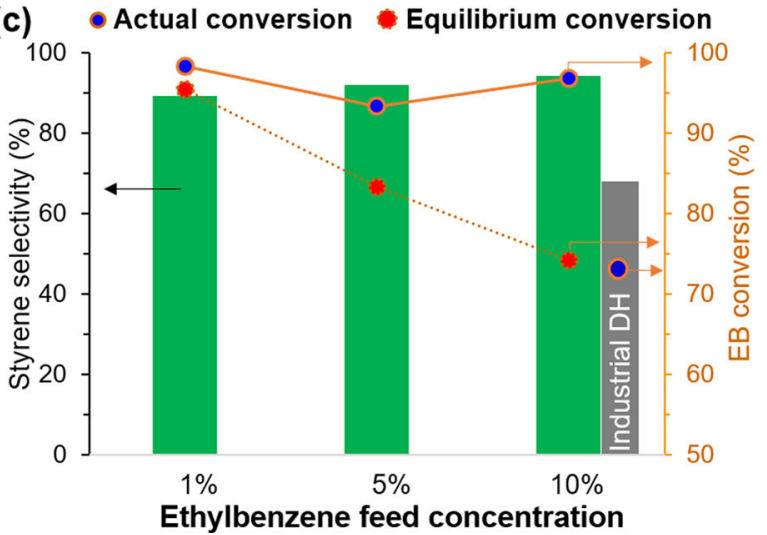

(d)

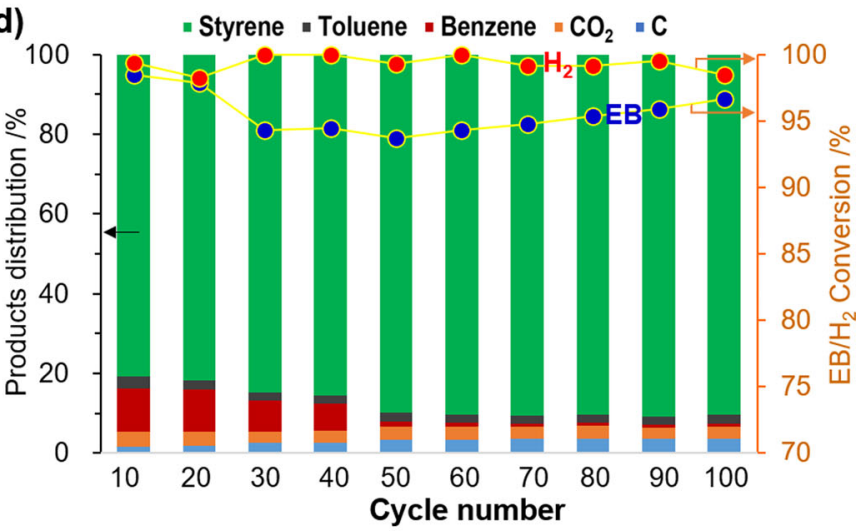

Fig. 2 Redox-ODH performance. Performance comparison of redox-ODH of ethylbenzene (EB) with a fully reoxidized and $\mathbf{b}$ partially reoxidized redox catalyst, $\mathrm{EB}$ partial pressure $=0.01 \mathrm{~atm}$, temperature $=600^{\circ} \mathrm{C}$. $\mathrm{ODH}$ performance comparing to $\mathrm{DH}$ equilibrium conversions in the range of $0.01-0.1$ atm ethylbenzene feed partial pressure (balance $\mathrm{Ar}$ ) using partially reoxidized redox catalyst. $\mathbf{d}$ Long-term cycle and product distributions in redox-ODH using fully reoxidized redox catalyst.

(absolute basis) than the maximum equilibrium yields for the conventional DH route. Compared to the practical yield in the commercial DH process, redox-ODH demonstrated 38\% yield increase (absolute basis) or $72 \%$ on a relative basis. In all cases, close to $100 \% \mathrm{H}_{2}$ were combusted to steam, ensuring autothermal operation while providing a protective atmosphere to maintain oxidation state of the catalytic surface without the needs for externally injected steam (Supplementary Fig. 2). Practically speaking, redox-ODH has the potential to operate at $1 \mathrm{~atm}$ ethylbenzene feed without steam dilution. The long-term stability of the redox catalyst was verified, as summarized in
Fig. 2d. Aside from a gradual increase in styrene selectivity over the first 50 cycles, stable and satisfactory redox catalyst performances were observed over the 100 cycle continuous testing with complete reoxidation of the redox catalyst. Coke formation was $<5 \%$ and was completely removed during the reoxidation step. It is noted that the redox-ODH performance relies on the participation of lattice oxygen species and deeply reduced (lattice oxygen-deprived) $(\mathrm{Ca} / \mathrm{Mn})_{1-x} \mathrm{O} @ \mathrm{KFeO}_{2}$ exhibits much lower ethylbenzene conversion and $\mathrm{H}_{2}$ by-product conversion (Supplementary Fig. 3). Further characterization of the redox catalyst and the reaction mechanism is discussed next. 
Redox catalyst characterizations. Figure $2 \mathrm{a}$ indicates that the degree of reoxidation of $(\mathrm{Ca} / \mathrm{Mn})_{1-x} \mathrm{O} @ \mathrm{KFeO}_{2}$ has a significant impact on the styrene selectivity. Since the redox catalyst's phases, surface elemental compositions, and surface structures undergo dynamic changes in the redox-ODH scheme, detailed understanding of such changes can reveal important mechanistic insights. Figure $3 \mathrm{a}$ shows the dynamic phase change observed with in situ X-ray diffraction (XRD) under cyclic ethylbenzene $\mathrm{ODH}$ and air reoxidation steps at $600{ }^{\circ} \mathrm{C}$. Under the styreneselective region (region 2 ), the primary phases observed include a $\mathrm{CaO}-\mathrm{MnO}$ solid solution phase and a potassium ferrite $\left(\mathrm{KFeO}_{2}\right)$ phase. The $\mathrm{CaO}-\mathrm{MnO}$ solid solution, with cation defects, continues to release lattice oxygen during the $\mathrm{ODH}$ step, as indicated by the continuous peak shift (from 40.5 to $39.9^{\circ}$ and from 34.9 to $\left.34.4^{\circ}\right)$. Over-reduction of $(\mathrm{Ca} / \mathrm{Mn})_{1-x} \mathrm{O} @ \mathrm{KFeO}_{2}$ formed metallic $\mathrm{Fe}$, which can be reversibly incorporated back into the redox catalyst. On the other hand, complete oxidation of $(\mathrm{Ca} / \mathrm{Mn})_{1-x}$ $\mathrm{O} @ \mathrm{KFeO}_{2}$ led to the dynamic exchange of cations between the $\mathrm{CaO}-\mathrm{MnO}$ solid solution and $\mathrm{KFeO}_{2}$, forming two new phases, that is, $\mathrm{Ca}_{2} \mathrm{Fe}_{2} \mathrm{O}_{5}$ and $\mathrm{K}_{0.296} \mathrm{Mn}_{0.926} \mathrm{O}_{2}$. $\mathrm{KFeO}_{2}$ is still observed in the fully oxidized redox catalyst. Detailed XRD peak assignment for (a) fully oxidized redox catalyst and (b) redox catalyst under redox-ODH operating regime are shown in Supplementary Fig. 4a, b. Transmission electron microscopy with energydispersive X-ray spectroscopy (TEM-EDS) further confirmed that $\mathrm{Ca}$ and $\mathrm{Mn}$ were segregated in separate phases for the fully oxidized redox catalyst (Supplementary Fig. 5). Partial reoxidation, however, prevents the formation of $\mathrm{K}_{0.296} \mathrm{Mn}_{0.926} \mathrm{O}_{2}$ (Supplementary Fig. 4c). The dynamic phase change observed with in situ XRD is consistent with the Mn and Fe oxidation state measurements obtained from X-ray photoelectron spectroscopy (XPS) for the redox catalyst at different reaction stages. Based on stoichiometry and literature ${ }^{46,47}, \mathrm{Mn}$ oxidation state in $\mathrm{K}_{0.296} \mathrm{Mn}_{0.926} \mathrm{O}_{2}$ is +4 , whereas in $\mathrm{CaO}-\mathrm{MnO}$ it is between +2 and +3 . As shown in Fig. $3 b$, it is observed in Mn $2 p$ XPS that peaks shift to lower binding energy (BE) by $1 \mathrm{eV}$ during the reaction stage. This corresponds to the phase transformation from $\mathrm{K}_{0.296} \mathrm{Mn}_{0.926} \mathrm{O}_{2}\left(\mathrm{Mn}^{4+}\right)$ to $\mathrm{CaO}-\mathrm{MnO}\left(\mathrm{Mn}^{3+/ 2+}\right)$. The XPS peak fittings on $\mathrm{Mn} 2 p_{3 / 2}$ peaks further agreed with this oxidation change, as shown in Supplementary Fig. 6. In comparison, $\mathrm{Fe} 2 p$ peaks stayed at the same BE for the oxidized and reduced samples (Fig. $3 \mathrm{c}$ ) and the oxidation state remained at $\mathrm{Fe}^{3+}$ (see Supplementary Fig. 6 for detailed peak fitting on $\mathrm{Fe} 2 p_{3 / 2}$ ). These results indicate that, within the operating regime, $\mathrm{Fe}$ oxidation state stayed constant at +3 resulting from the "sacrificial" reduction of $\mathrm{Mn}^{3 / 4+}$. Given that $\mathrm{KFeO}_{2}$ with $\mathrm{Fe}$ oxidation state being +3 is known to be the active phase for $\mathrm{DH}$ of ethylbenzene ${ }^{48}$, the presence of $\mathrm{Mn}$ in the redox catalyst not only helps to maintain $\mathrm{Fe}$ at a desirable oxidation state but also provides the lattice oxygen donation/storage capabilities. These
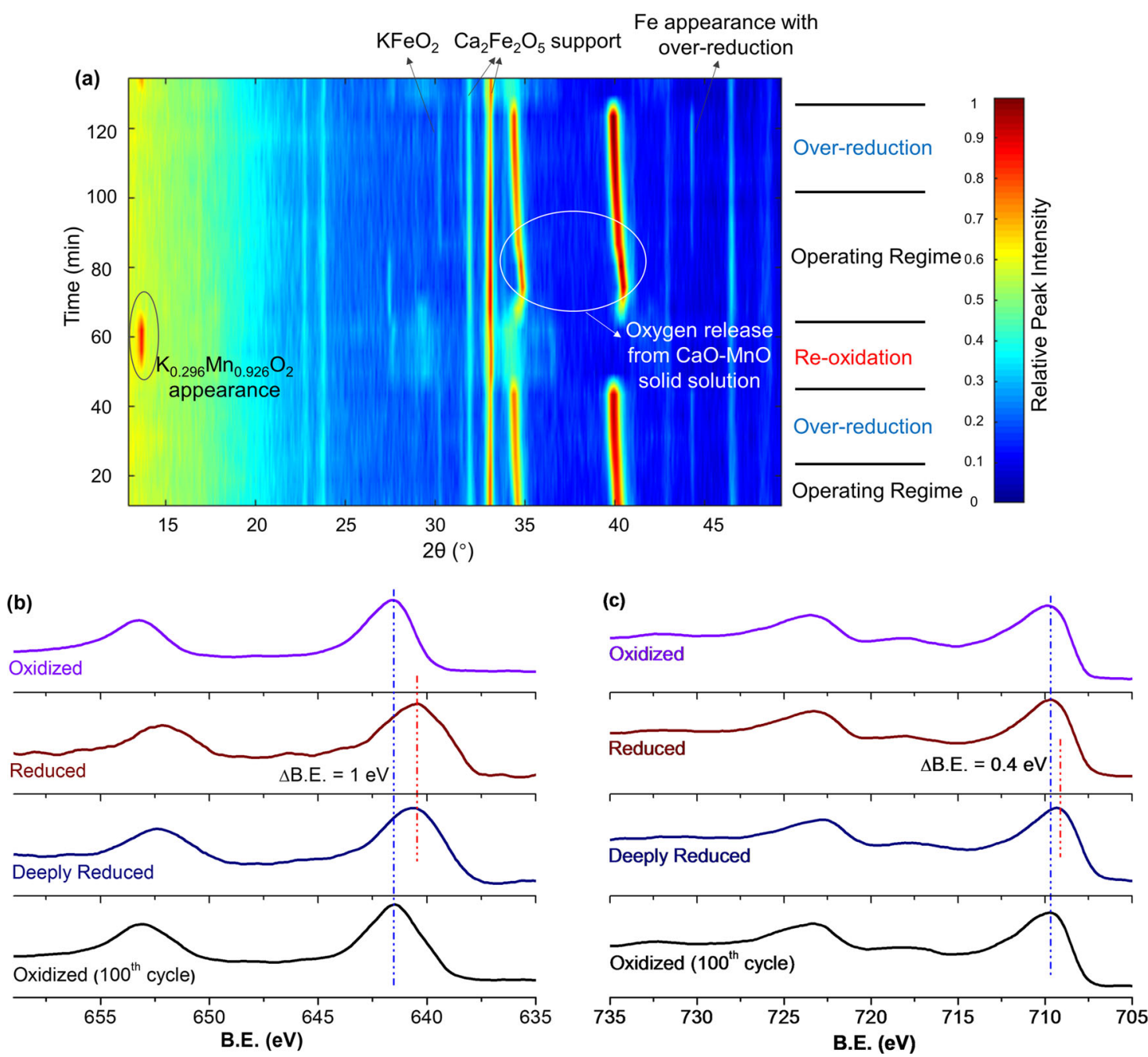

Fig. 3 Structural evolution of the redox catalyst. a In situ XRD under cyclic ethylbenzene $\mathrm{ODH}$ and air reoxidation steps at $600{ }^{\circ} \mathrm{C}$; and $\mathrm{XPS}$ of $\mathrm{Mn} 2 p$ (b) and Fe $2 p$ (c) for redox catalysts at different reaction stages. 


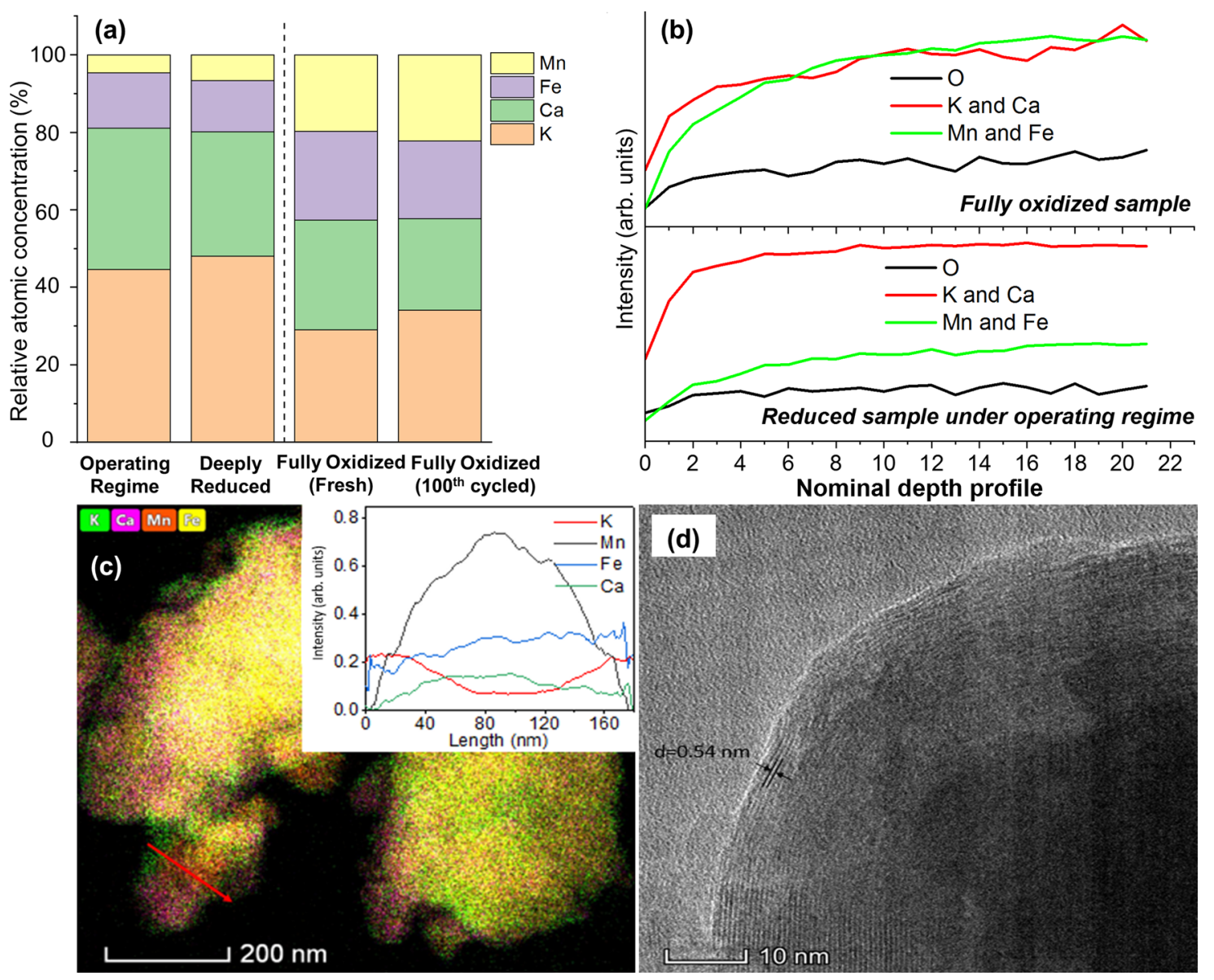

Fig. 4 Surface and morphology characterizations of the redox catalyst. a XPS surface elemental composition, $\mathbf{b}$ low-energy ion scattering (LEIS) depth profiling, $\mathbf{c}$ EDS and line scan, and $\mathbf{d}$ high-resolution TEM of surface structure.

results are further confirmed by Mössbauer spectroscopy measurements (Supplementary Fig. 7), where fully oxidized and reduced $(\mathrm{Ca} / \mathrm{Mn})_{1-x} \mathrm{O} @ \mathrm{KFeO}_{2}$ under operating scheme exhibited consistent $\mathrm{Fe}$ oxidation states. It is also noted that deep reduction of $(\mathrm{Ca} / \mathrm{Mn})_{1-x} \mathrm{O} @ \mathrm{KFeO}_{2}$, which is outside our typical operating regime, reduces $\mathrm{Fe}$ oxidation state as seen by the downward shift in BE by $0.4 \mathrm{eV}$. This is consistent with the observation of metallic iron under XRD and is accompanied with a decrease in catalytic activity due to the lack of active lattice oxygen for redox-ODH (Supplementary Fig. 3). The majority of the iron cations, however, remain at +3 state.

Besides the dynamic phase/oxidation state changes, $(\mathrm{Ca} / \mathrm{Mn})_{1-x} \mathrm{O} @ \mathrm{KFeO}_{2}$ also undergoes dynamic surface composition and structure changes during redox-ODH of ethylbenzene. The surface elemental composition change, determined by XPS, is illustrated in Fig. 4a. XPS shows that the surface of fully oxidized $(\mathrm{Ca} / \mathrm{Mn})_{1-x} \mathrm{O} @ \mathrm{KFeO}_{2}$ contains a significant amount of $\mathrm{Mn}$ (23\%) and $\mathrm{Fe}(20 \%)$. On the other hand, reduced redox catalyst is highly K-enriched and the presence of surface $\mathrm{Mn}$ was reduced by $\sim 5$-folds. The surface enrichment of $\mathrm{K}$ on reduced samples was further confirmed with LEIS spectroscopy, which can detect the composition of topmost surface layers of a redox catalyst ${ }^{49}$. LEIS confirmed that the reduced samples are enriched with $\mathrm{K}$ and surface $\mathrm{Mn} / \mathrm{Fe}$ are significantly suppressed (Fig. $4 \mathrm{~b}$ ). These were also confirmed with TEM-EDS in Fig. 4c, d. Consistent with in situ XRD results, EDS on fully oxidized sample showed a segregation between $\mathrm{Ca}$ and $\mathrm{Mn}$, with no surface enrichment feature clearly observed (Supplementary Fig. 5). In comparison, the reduced sample, within the operating range of redox-ODH, showed a surface enrichment of $\mathrm{K}$ and a bulk enrichment of $\mathrm{Mn}$ as shown by the EDS line scan (Fig. 4c). High-resolution TEM showed that the surface structure of the partially oxidized sample belongs to (101) plane of crystalline $\mathrm{KFeO}_{2}$ phase, according to the $d$-spacing (Fig. $4 \mathrm{~d}$ ). This shows that a core-shell structure is formed on redox catalyst under its operating condition, where the core is $\mathrm{MnOx}$-enriched $\left((\mathrm{Ca} / \mathrm{Mn})_{1-x} \mathrm{O}\right)$ and the shell is a layer of $\mathrm{KFeO}_{2}$.

Reaction mechanism study. Ethylbenzene Fourier transform infrared spectroscopy (FTIR) with both temperature-programmed surface reaction (TPSR) and isothermal mode were further conducted to determine the surface properties of the core-shell structured redox catalyst. As can be seen in Fig. 5a for TPSR experiment on the operating range $(\mathrm{Ca} / \mathrm{Mn})_{1-x} \mathrm{O} @ \mathrm{KFeO}_{2}$, chemisorption of ethylbenzene on the catalyst surface leads to the formation of bicarbonate and a notable amount of polystyrene species at $100^{\circ} \mathrm{C}$, which subsequently disappeared at $200^{\circ} \mathrm{C}$. As reported by $\mathrm{Wu}$ and coworkers ${ }^{13}$ on a high-surface-area $\mathrm{CeO}_{2}$ catalyst ${ }^{13}$, the polystyrene species are precursors for coke formation. The absence of the polystyrene peak at operating temperatures for $(\mathrm{Ca} / \mathrm{Mn})_{1-x} \mathrm{O} @ \mathrm{KFeO}_{2}$ indicates a lower tendency for coke formation on the redox catalyst. The peak around $1600 \mathrm{~cm}^{-1}$ was characterized to be bicarbonate instead of deposited carbon based on fitting of other peaks and this bicarbonate was converted to carbonate at elevated temperatures ${ }^{50}$. In addition, a vinyl overtone peak appeared at $1800 \mathrm{~cm}^{-1}$, which corresponds to the formation of surface styrene species ${ }^{13}$. Isothermal FTIR was 

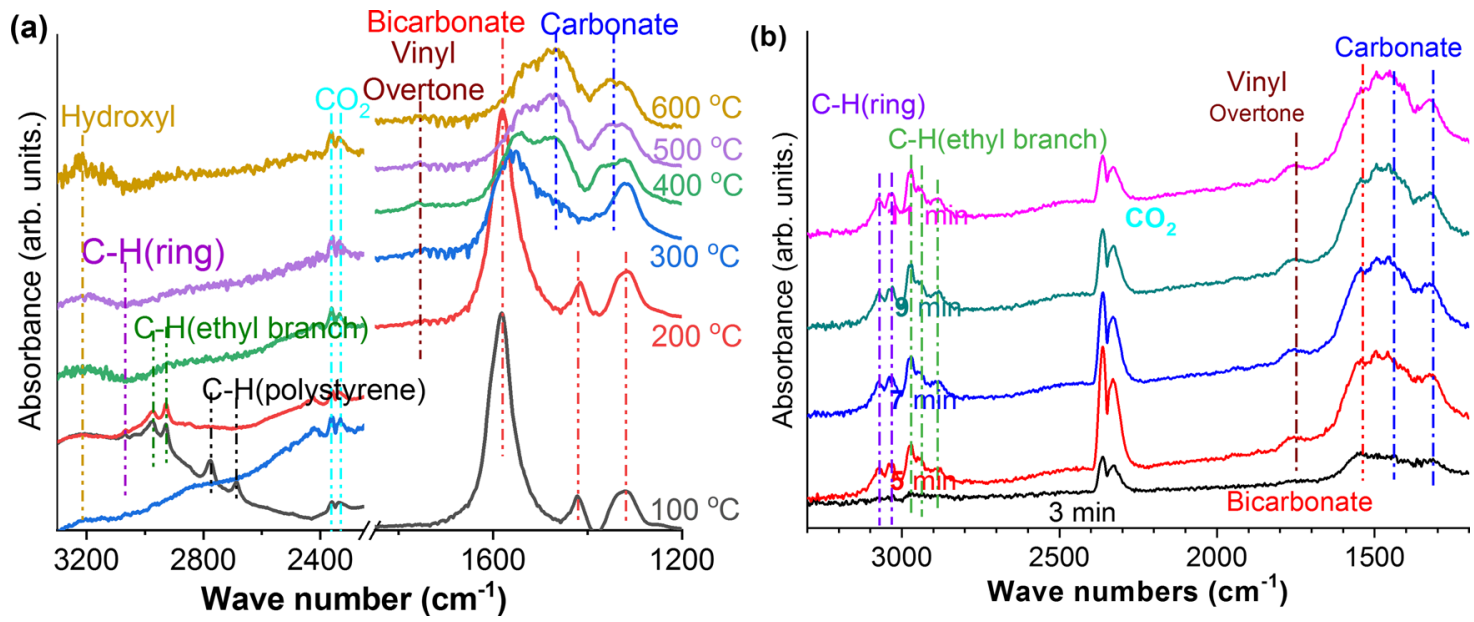

Fig. 5 In situ IR spectra analysis. In situ IR spectra collected during a TPSR on $(\mathrm{Ca} / \mathrm{Mn})_{1-x} \mathrm{O}_{0} @ \mathrm{KFeO}_{2}$ from 100 to $500^{\circ} \mathrm{C}$ and $\mathbf{b}$ isothermal ethylbenzene $\mathrm{ODH}$ on fully oxidized $(\mathrm{Ca} / \mathrm{Mn})_{1-x} \mathrm{O} @ \mathrm{KFeO}_{2}$ at $500{ }^{\circ} \mathrm{C}$.

conducted in Fig. 5b, with continuous ethylbenzene feed on fully oxidized $(\mathrm{Ca} / \mathrm{Mn})_{1-x} \mathrm{O} @ \mathrm{KFeO}_{2}$. Both polystyrene and coke peaks were absent, whereas styrene was formed based on the presence of the vinyl peak. The trend for $\mathrm{CO}_{2}$ peaks matched well with the reactivity performance shown in Fig. 2a, where $\mathrm{CO}_{2}$ selectivity is high during the oxidized stage (region 1), whereas styrene selectivity dominates within the operating regime (region 2). A stable carbonate species was still observed but it does not appear to affect the catalyst activity. The formation of carbonate species on the ethylbenzene-contacted redox catalyst was also confirmed by XPS peak fittings of the O $1 s$ peak, as shown in Supplementary Fig. 8. The FTIR results indicate that surface polystyrene species formed on $(\mathrm{Ca} / \mathrm{Mn})_{1-x} \mathrm{O} @ \mathrm{KFeO}_{2}$ were further decomposed into styrene rather than coke and the redox catalyst was largely immune to coke formation. This is consistent with the product distribution results in Fig. 2a. Raman was further conducted on used redox catalyst after ethylbenzene $\mathrm{ODH}$ and confirmed the minimal amount of carbon deposition (Supplementary Fig. 9).

Based on the structural information obtained, it can be concluded that a layer of $\mathrm{KFeO}_{2}$ predominantly covers the redox catalyst surface, whereas lattice oxygen from the $(\mathrm{Ca} / \mathrm{Mn})_{1-{ }_{x} \mathrm{O}}$ solid solution reversibly donates its lattice oxygen for the redox$\mathrm{ODH}$ reaction. DFT simulations were hence conducted on $\mathrm{KFeO}_{2}$ (124) surface, which is one of its most stable crystal surfaces ${ }^{51}$. The Cartesian coordinates of each important transition state were attached in the Vienna ab initio simulation package POSCAR format in the Supplementary material. Various orientations of ethylbenzene adsorption on $\mathrm{KFeO}_{2}$ were considered and the most stable adsorbed configuration was determined (Supplementary Fig. 10), shown as configuration I in Fig. 6a. C-H dissociation from $\alpha-C$ is considered as the first hydrogen dissociation step due to its much lower (thermodynamic) reaction energy $(0.08 \mathrm{eV})$ than the $\mathrm{H}$ abstraction from $\beta-\mathrm{C}(0.91 \mathrm{eV})$ (Supplementary Fig. 11). $\beta-\mathrm{H}$ dissociation is considered as the second reaction step. Compared with direct $\mathrm{H}$ transfer, slightly shifting of the $\mathrm{C}_{8} \mathrm{H}_{9}$ toward the target lattice oxygen (from configuration II to II in Fig. 6a) can reduce the distance between the $\beta-\mathrm{H}$ and the target oxygen from 3.55 to $2.41 \AA$. This largely reduces the steric hindrance and thereby lowering the barrier for $\beta-\mathrm{H}$ abstraction from 1.76 to $0.37 \mathrm{eV}$ with a transition state of ethyl branch attached in parallel to the $\mathrm{KFeO}_{2}$ surface (configuration TS-[IIIII] in Fig. 6a). Electron density shifts in the transition state structures of $\alpha$ and $\beta$ hydrogen abstraction are depicted in Supplementary Fig. S12a, b, showing that electrons tend to transfer from the $\mathrm{C}-\mathrm{H}$ bonds to $\mathrm{O}-\mathrm{H}$ bonds, which correspond to the trends of $\mathrm{C}-\mathrm{H}$ bonds cleavage and $\mathrm{O}-\mathrm{H}$ bonds formation. DFT calculation also indicated that a transition state via $\mathrm{C}-\mathrm{H}$ dissociation from the benzene ring is not likely (Supplementary Fig. 13). The computed activation energies of $\alpha$ and $\beta$ hydrogen abstraction $(0.70$ and $0.37 \mathrm{eV})$ are much lower than those reported over other catalyst surfaces, such as $\mathrm{V}_{2} \mathrm{O}_{5}$ (001) (1.96 and $2.23 \mathrm{eV})^{52}, \mathrm{CeO}_{2}(111)(1.70 \text { and } 0.84 \mathrm{eV})^{53}$, and zirconium vanadate $(2.48 \text { and } 1.23 \mathrm{eV})^{54}$, showing the advantages of our proposed catalyst. Following the $\alpha$ and $\beta$ hydrogen abstraction, the formed styrene readily desorbs from the catalyst surface with highly favorable energetics. The low tendency for styrene adsorption on the surface also explains the excellent selectivity observed experimentally. This finding is consistent with literatures, where $\mathrm{KFeO}_{2}$ was identified as the active phase for ethylbenzene $\mathrm{DH}$ in styrene $5,48,55,56$.

Meanwhile, DH of ethylbenzene to styrene leaves two hydroxyls $(-\mathrm{OH})$ on the $\mathrm{KFeO}_{2}$ surface. To complete the $\mathrm{ODH}$ reaction, a proton from one $-\mathrm{OH}$ needs to migrate to an adjacent $-\mathrm{OH}$ site to form water, which then desorbs from the surface. However, this process is highly endothermic with a prohibitively high barrier of $2.33 \mathrm{eV}$. Further investigation indicated that the formation of water from unselective combustion of hydrocarbons and/or in situ selective combustion of hydrogen further facilitates $\mathrm{ODH}$ activity, as indicated in Fig. 6a-2. As can be seen, the energy barrier for water formation decreased to $0.47 \mathrm{eV}$ under a water-assisted proton transfer mechanism. Here, a hydrogen bond formed between a hydroxyl and water molecule. The hydrogen bond, formed in situ under redox-ODH, facilitates proton transfer on the $\mathrm{KFeO}_{2}$ surface, leading to more than 4folds decrease in the energy barrier for water formation. A similar water-assisted proton transfer phenomena were reported by Merte et al. ${ }^{57}$ as determined by DFT and scanning tunneling microscopy on a FeO thin film. We also explored the effect of water on $\alpha$ and $\beta$ hydrogen abstraction and did not observe any enhancement effect, indicating that water does not participate in these steps. As such, the overall reaction pathway is summarized in Fig. 6a. The key findings include: (1) $\alpha$-hydrogen abstraction is the rate-limiting step for ethylbenzene ODH; (ii) water molecules formed from in situ combustion of hydrogen plays an important role in facilitating the $\mathrm{ODH}$ reaction, highlighting the importance of the $(\mathrm{Ca} / \mathrm{Mn})_{1-x} \mathrm{O}$ solid solution in terms of providing active lattice oxygen for hydrogen combustion; (iii) styrene molecules readily desorbs from the $\mathrm{KFeO}_{2}$ surface, supporting the high catalytic activity/selectivity of $(\mathrm{Ca} / \mathrm{Mn})_{1-x} \mathrm{O} @ \mathrm{KFeO}_{2}$ and the importance of maintaining a $\mathrm{KFeO}_{2}$ terminated surface. 

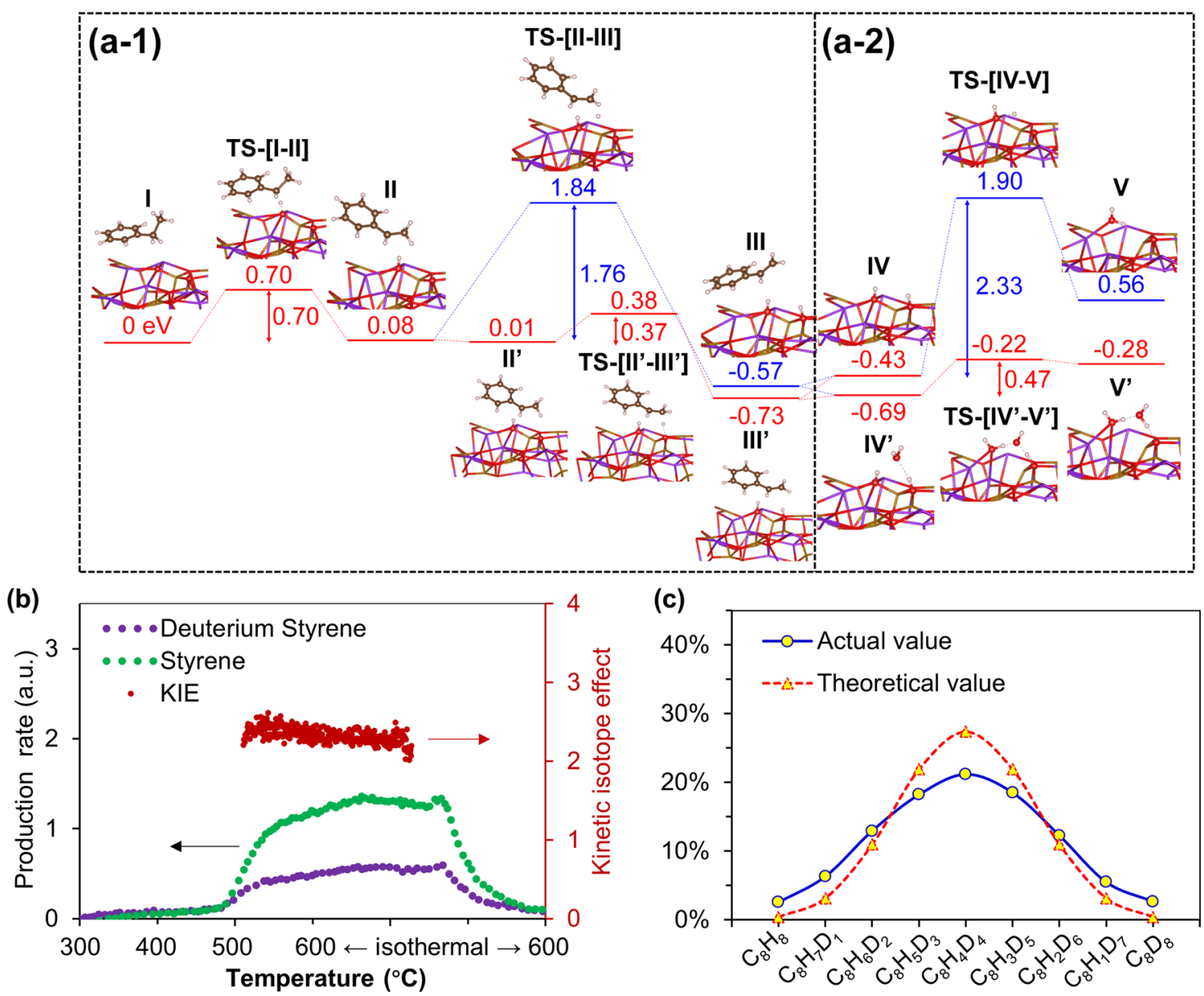

Fig. 6 Reaction pathway and rate-limiting step. a Computed energy potential profiles of each elementary step for the ethylbenzene ODH and waterassisted proton transfer and water formation (a-1 corresponds to dehydrogenation steps and $\mathbf{a - 2}$ corresponds to water formation and desorption steps). b Kinetic isotope effect study with both temperature-programmed reduction and isothermal reduction of the redox catalyst using ethylbenzene and deuterium ethylbenzene. c Styrene isotopes distribution from isothermal ODH using co-feed of ethylbenzene and deuterium ethylbenzene.

The DFT calculation results are further supported by experimental data. For instance, isotope exchange between $\mathrm{H}$ hydroxylated $(\mathrm{Ca} / \mathrm{Mn})_{1-x} \mathrm{O} @ \mathrm{KFeO}_{2}$ and deuterated ethylbenzene in FTIR-TPSR experiments indicated that only the Ds from the ethyl branch of ethylbenzene were activated/exchanged $<200{ }^{\circ} \mathrm{C}$ (Supplementary Fig. 14). This confirms that $\alpha$ and $\beta$ hydrogen abstraction being the critical first steps for ethylbenzene ODH. To further determine the rate-limiting step, kinetic isotope effect (KIE) for the ODH reaction rates of ethylbenzene $\left(\mathrm{C}_{8} \mathrm{H}_{10}\right)$ and deuterated ethylbenzene $\left(\mathrm{C}_{8} \mathrm{D}_{10}\right)$ were measured (Fig. 6b). The KIE values were determined to be between 2.12 and 2.62. This confirms that the $\mathrm{C}-\mathrm{H}$ bond activation on the ethyl branch of ethylbenzene being the rate-limiting step ${ }^{58}$ and is consistent with the DFT results. Another interesting experimental finding via co-feeding of $\mathrm{C}_{8} \mathrm{H}_{10}$ and $\mathrm{C}_{8} \mathrm{D}_{10}$ (Fig. 6c) is that the resulting styrene isotopes with different amount of $\mathrm{D}$ substitution almost follows a Gaussian distribution. This is only possible in the case of a perfect isotope scrambling, where all $\mathrm{H}$ in $\mathrm{C}_{8} \mathrm{H}_{10}$ have the same chance of being exchanged into D. This confirms that: (a) as-formed styrene molecules are absorbed parallel to the $\mathrm{KFeO}_{2}$ surface in a conjugated electronic structure (consistent with DFT calculated configuration III in Fig. 6a-1); (b) water molecules are likely to facilitate proton exchange. The effect of water on proton exchange (and hence ethylbenzene conversion and water formation/desorption) was further confirmed with $\mathrm{KFeO}_{2}$ without $(\mathrm{Ca} / \mathrm{Mn})_{1-x} \mathrm{O}$. Without coinjection of water, stand-alone $\mathrm{KFeO}_{2}$ cannot donate its lattice oxygen for in situ water formation, showed low ethylbenzene conversion (44.3\%) and the $\mathrm{H}_{2}$ by-product was not effectively oxidized to water (Supplementary Fig. 15). Overall, these mechanistic findings, supported by both experiment and DFT calculations, provide important insights for redox catalyst design and optimizations.

Process performance and impacts. To quantify the practical impacts of the $(\mathrm{Ca} / \mathrm{Mn})_{1-x} \mathrm{O} @ \mathrm{KFeO}_{2}$ redox catalyst in the context of the redox-ODH scheme, detailed ASPEN Plus simulations were carried out to simulate both the commercial DH and redox$\mathrm{ODH}$ schemes. The process configuration and operating conditions for commercial ethylbenzene DH process were documented in detail by Luyben ${ }^{8}$. As detailed in the Supplementary document, our simulation accurately reproduced the performance of the commercial DH process (Case 1 in the Supplementary document). Two cases for the redox-ODH process were also analyzed: (1) The base case (Case 2) evaluates the redox-ODH process using the experimental performance of the $(\mathrm{Ca} / \mathrm{Mn})_{1-x} \mathrm{O} @ \mathrm{KFeO}_{2}$ redox catalyst at $0.1 \mathrm{~atm}$ ethylbenzene feed pressure, assuming $90 \%$ steam dilution; (2) An optimal case (Case 3), also using the experimental performance but assuming no steam dilution, was considered as well. We note that ethylbenzene was injected in dry conditions without steam dilution in all our experimental cases. These results support the potential feasibility of Case 3, that is, complete avoidance of steam usage in redox-ODH of ethylbenzene. 


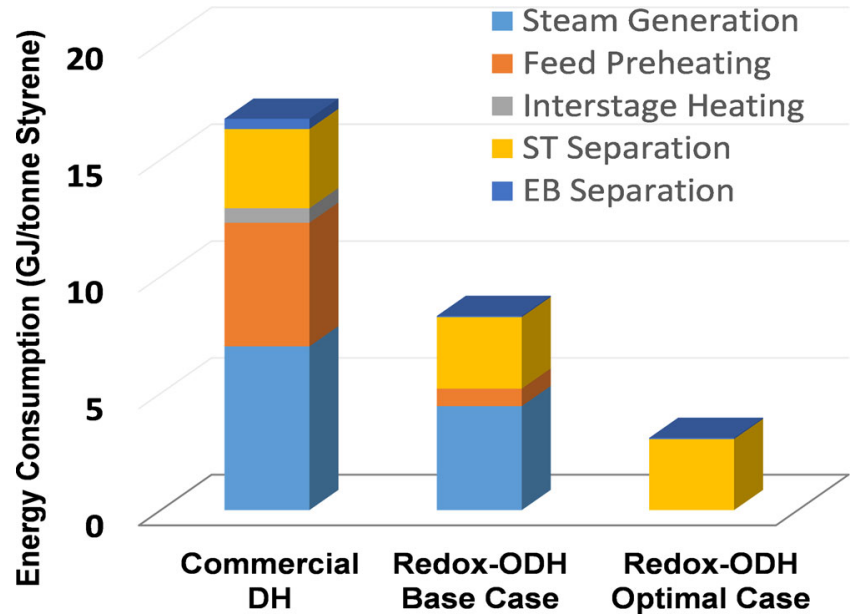

Fig. 7 Process analyses. Energy intensities of commercial DH and redox$\mathrm{ODH}$ for styrene production based on ASPEN Plus simulation.

Figure 7 summarizes the process performance of the three cases. As can be seen, $50-82 \%$ energy savings can be anticipated from the redox-ODH cases, with steam generation (including heating/reheating) being the main driver for energy consumptions. Given that the energy is provided by fossil fuels in styrene production, $\mathrm{CO}_{2}$ emission can be reduced by up to $79 \%$ with the redox-ODH approach (accounting for offset with hydrogen byproduct in commercial DH). The significant energy/emission savings by redox-ODH are primarily driven by the improved energy management and reduced steam usage. In the commercial DH process, a large steam dilution ratio $(\sim 22: 1)$ is used. Moreover, steam needs to be superheated to provide the heat for the highly endothermic DH reaction. As a result, $12.3 \mathrm{GJ}$ of energy is required for steam generation and reheating in order to produce each metric ton of the styrene product. In contrast, the base case redox-ODH significantly reduces steam usage (9:1 dilution ratio). Moreover, the exothermic ODH reaction offsets the energy consumption for steam heating/reheating, leading to a net energy consumption of $5.2 \mathrm{GJ} /$ ton of styrene. This energy consumption can be eliminated given that redox-ODH does not need steam co-feed in principle. Besides the energy savings for steam generation, redox-ODH is more efficient in all the other key process steps. Particularly, the high product selectivity and yield leads to reduced amount of recycling as well as decreased energy consumptions for ethylbenzene and styrene separations with a smaller number of separation trays. The high styrene selectivity in redox-ODH provides an overall styrene yield of $91.4 \%$, or $38 \%$ higher than that in the commercial DH process (53.1\%). These process analysis results clearly demonstrate the advantages of the $(\mathrm{Ca} / \mathrm{Mn})_{1-x} \mathrm{O} @ \mathrm{KFeO}_{2}$ redox catalyst and the redox-ODH process scheme.

The current study proposed and demonstrated a redox-ODH approach that autothermally converts ethylbenzene to styrene with $91.4 \%$ overall yield and $50-82 \%$ energy and $\mathrm{CO}_{2}$ emission savings, when compared to the commercial styrene $\mathrm{DH}$ process. To facilitate ethylbenzene conversion, a tailored, multifunctional redox catalyst, which acts as a heterogeneous catalyst, an oxygen separation agent, and a selective oxidation material, was developed and characterized. In redox-ODH, the $(\mathrm{Ca} / \mathrm{Mn})_{1-x} \mathrm{O} @ \mathrm{KFeO}_{2}$ redox catalyst not only catalyzes ethylbenzene conversion but also donates its active lattice oxygen for selectively hydrogen combustion in a recyclable manner. Ninety-seven percent ethylbenzene single-pass conversion, $94.2 \%$ styrene selectivity, and $\sim 100 \% \mathrm{H}_{2}$ conversion was achieved without co-feeding steam. Detailed characterizations indicate that the redox catalyst undergoes dynamic bulk and surface structural changes. Under the working conditions, $(\mathrm{Ca} / \mathrm{Mn})_{1-x} \mathrm{O} @ \mathrm{KFeO}_{2}$ is terminated with a $\mathrm{KFeO}_{2}$ rich surface, which is responsible for catalyzing ethylbenzene conversion. Meanwhile, its bulk phase is composed of a cation defected $\mathrm{CaO}-\mathrm{MnO}$ solid solution that is responsible for reversible lattice oxygen donation (in the $\mathrm{ODH}$ step) and uptake (in the reoxidation step). The lattice oxygen donation was facilitated by $\mathrm{Mn}+3$ to +2 transition and the "sacrificial" reduction of $\mathrm{Mn}$ cations helps to stabilize the oxidation state of Fe, which remains at its most catalytically active +3 state. Moreover, the facile donation of lattice oxygen also retards coke formation. Through DFT calculations along with experimental validations, a detailed reaction pathway for the redox-ODH reaction on the $\mathrm{KFeO}_{2}$ surface was established. It was determined that a hydrogen abstraction is the rate-limiting step for ethylbenzene $\mathrm{ODH}$ and water molecules formed in situ significantly lowers the energy barrier for hydrogen combustion via a water-assisted proton transfer mechanism. Moreover, styrene molecules readily desorb from the $\mathrm{KFeO}_{2}$ surface, ensuring high product selectivity. These findings, which unveil the roles of the $\mathrm{KFeO}_{2}$ surface,

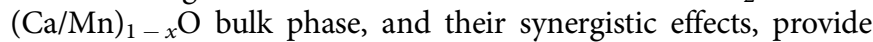
important mechanistic insights for designing effective redox catalysts for alkylbenzene conversions. Finally, detailed process simulations based on experimental data indicate up to $82 \%$ reduction in energy consumption and $79 \%$ decrease in $\mathrm{CO}_{2}$ emissions. This potentially translates into $\sim 14$ million tonnes of $\mathrm{CO}_{2}$ emission reductions each year for this important yet carbonintensive industrial process.

\section{Methods}

Redox catalyst synthesis. The $(\mathrm{Ca} / \mathrm{Mn})_{1-x} \mathrm{O} @ \mathrm{KFeO}_{2}$ redox catalyst was prepared in two steps. The $(\mathrm{Ca} / \mathrm{Mn})_{1-x} \mathrm{O}$ substrate was synthesized by a modified Pechini method. $\mathrm{Mn}\left(\mathrm{NO}_{3}\right)_{2} \cdot 4 \mathrm{H}_{2} \mathrm{O}(8.26 \mathrm{~g}, 97.0 \%$, Sigma-Aldrich $)$ and $\mathrm{Ca}$ $\left(\mathrm{NO}_{3}\right)_{2} \cdot 4 \mathrm{H}_{2} \mathrm{O}(8.77 \mathrm{~g}, 99.0 \%$, Sigma-Aldrich) were dissolved in deionized water with stirring at $30^{\circ} \mathrm{C}$. Citric acid $(26.87 \mathrm{~g}, 99.5 \%$, Sigma-Aldrich) was then added into the solution. Next, $11.7 \mathrm{ml}$ ethylene glycol (99.8\%, Sigma-Aldrich) was added to the solution. The obtained solution was kept at $80^{\circ} \mathrm{C}$ with stirring until a gel formation. The gel was then transferred to an oven for drying at $130^{\circ} \mathrm{C}$ for $24 \mathrm{~h}$ The precursor was finally calcined in a furnace at $950^{\circ} \mathrm{C}$ for $12 \mathrm{~h}\left(5^{\circ} \mathrm{C} / \mathrm{min}\right.$ ramping rate) under continuous airflow. The sample obtained after calcination was crushed into $20-40$ mesh. $(\mathrm{Ca} / \mathrm{Mn})_{1-x} \mathrm{O} @ \mathrm{KFeO}_{2}$ was synthesized via wet impregnation by using $(\mathrm{Ca} / \mathrm{Mn})_{1-{ }_{x}} \mathrm{O}$ as the substrate. Weigh $4 \mathrm{~g}$ of the $(\mathrm{Ca} / \mathrm{Mn})_{1-x} \mathrm{O}$ substrate synthesized and put into a glass beaker. Weigh $0.91 \mathrm{~g}$ of $\mathrm{KNO}_{3}\left(99.9 \%\right.$, Sigma-Aldrich) and $18.10 \mathrm{~g}$ of $\mathrm{Fe}\left(\mathrm{NO}_{3}\right)_{3} \cdot 9 \mathrm{H}_{2} \mathrm{O}(98 \%$, SigmaAldrich) into another glass beaker and add deionized water to dissolve these. The formed solution was then added into the $(\mathrm{Ca} / \mathrm{Mn})_{1-x} \mathrm{O}$-containing beaker and stirred at $80^{\circ} \mathrm{C}$ until dried. The obtained mixture was calcined in a furnace under air continuous flow at $650^{\circ} \mathrm{C}$ for $3 \mathrm{~h}$, and then crushed into $20-40$ mesh as final $(\mathrm{Ca} / \mathrm{Mn})_{1-x} \mathrm{O} @ \mathrm{KFeO}_{2}$ redox catalyst. Stand-alone $\mathrm{KFeO}_{2}$ was synthesized by adding equal molar amounts of $\mathrm{KNO}_{3}$ and $\mathrm{Fe}\left(\mathrm{NO}_{3}\right)_{3} \cdot 9 \mathrm{H}_{2} \mathrm{O}$ into a glass beaker. Specifically, $3.18 \mathrm{~g} \mathrm{KNO}_{3}$ and $12.73 \mathrm{~g} \mathrm{Fe}\left(\mathrm{NO}_{3}\right)_{3} \cdot 9 \mathrm{H}_{2} \mathrm{O}$ were added into a glass beaker, and water was then added into the beaker. The solution was stirred at $80^{\circ} \mathrm{C}$ until dried. The resulting solids were calcined in a furnace under air continuous flow at $650{ }^{\circ} \mathrm{C}$ for $3 \mathrm{~h}$ to obtain stand-alone $\mathrm{KFeO}_{2}$.

Ethylbenzene redox-ODH reactivity test. Ethylbenzene redox-ODH was conducted via a cyclic experiment. Ethylbenzene ODH step was conducted first. In this step, $0.5 \mathrm{~g}$ of redox catalyst was loaded into a fixed bed quartz U-tube reactor with ID of $1 / 8$ in. The $\mathrm{U}$-tube reactor was heated via a furnace equipped with a K-type thermocouple. Typical ethylbenzene ODH reaction was conducted at $600{ }^{\circ} \mathrm{C}$. Ethylbenzene vapor was introduced into the $\mathrm{U}$-tube reactor via a bubbler setup in Supplementary Fig. 1. The bubbler was heated in an oil bath. Ar gas $(25 \mathrm{ml} / \mathrm{min})$ was introduced into the bubbler, and the exit gas was Ar/ethylbenzene mixture. The ethylbenzene partial pressure was adjusted by changing the temperature of the oil bath. For example, the oil bath was set at $25^{\circ} \mathrm{C}$ to obtain an ethylbenzene partial pressure of $\sim 0.01 \mathrm{~atm}$. The ethylbenzene ODH step lasted for $30 \mathrm{~min}$. The products were detected and quantified via a downstream quadruple mass spectroscopy (QMS, MKS Cirrus II) or gas chromatography (Agilent 7890A). After the ethylbenzene ODH step, the U-tube reactor was purged for $20 \mathrm{~min}$. Then, simulated air ( $25 \mathrm{ml} / \mathrm{min}, 20 \% \mathrm{O}_{2}$ balanced in $\mathrm{Ar}$ ) was introduced into the heated U-tube reactor at $600{ }^{\circ} \mathrm{C}$ for the air reoxidation step. The air reoxidation step lasted for $5 \mathrm{~min}$ for a redox catalyst full reoxidation, and for 2 min for a redox catalyst partial reoxidation. 
Catalyst characterization. The exothermicity and the weight change of $\mathrm{H}_{2} / \mathrm{O}_{2}$ redox cycles with $(\mathrm{Ca} / \mathrm{Mn})_{1-x} \mathrm{O} @ \mathrm{KFeO}_{2}$ redox catalyst were measured on a thermogravimetric analyzer (TGA) equipped with differential scanning calorimetry. Approximately 50 micrograms of redox catalysts were loaded into the crucible cell of the TGA (TA instrument). Then, the TGA cell was heated to $600{ }^{\circ} \mathrm{C}$ with $10^{\circ} \mathrm{C} /$ min under Ar. $\mathrm{H}_{2} / \mathrm{O}_{2}$ redox cycles were conducted under $600^{\circ} \mathrm{C}$. First, $10 \% \mathrm{H}_{2}$ (balanced in $\mathrm{Ar}$ ) was introduced for $5 \mathrm{~min}$ as the redox catalyst reduction step. Then, the cell was purged with pure Ar for $5 \mathrm{~min}$. After that, $20 \% \mathrm{O}_{2}$ (balanced in $\mathrm{Ar}$ ) was introduced for $5 \mathrm{~min}$ as the redox catalyst reoxidation step. Another $5 \mathrm{~min}$ Ar-purging step was followed after that to finish one redox cycle. The redox cycle was repeated for ten times and a stabilized exothermicity/weight change was achieved.

In situ XRD experiments were conducted on an Empyrean X-ray diffractometer equipped with an Anton-Parr XRK-900 reactor chamber. A scanning range of $10-50^{\circ}(2 \theta)$ was used to obtain XRD patterns by using $\mathrm{Cu} \mathrm{Ka}(\lambda=0.1542 \mathrm{~nm})$ radiation operating at $45 \mathrm{kV}$ and $40 \mathrm{~mA}$. To determine the phase behavior and stability of the catalyst, a ethylbenzene temperature-programmed reduction (TPR) in the range $300-650{ }^{\circ} \mathrm{C}$ (ethylbenzene-TPR) and isothermal redox at $600{ }^{\circ} \mathrm{C}$ were performed. Before the redox, fresh catalyst was loaded into the chamber and scanned to obtain a pattern at room temperature. Before the experiment, the reaction system (reactor chamber, ethylbenzene bubbler, and connected gas line) are sufficiently purged to remove air and possible contaminants. In ethylbenzeneTPR experiment, the reactor chamber was first heated to $300^{\circ} \mathrm{C}$ under a flow of nitrogen at a flow rate of $25 \mathrm{ml} / \mathrm{min}$. Prior to the ethylbenzene-TPR, the nitrogen was switched to ethylbenzene bubbler at room temperature $\left(25^{\circ} \mathrm{C}\right)$ to generate a ethylbenzene/nitrogen flow with a ethylbenzene partial pressure of $\sim 1 \%$. The sample was heated in ethylbenzene/nitrogen in the range $300-650{ }^{\circ} \mathrm{C}$ at a rate of $2{ }^{\circ} \mathrm{C} / \mathrm{min}$. Afterwards, the temperature decreased to $600^{\circ} \mathrm{C}$ at a rate of $10^{\circ} \mathrm{C} / \mathrm{min}$ and then kept at $600^{\circ} \mathrm{C}$ for $48 \mathrm{~min}$ with the continuous ethylbenzene/nitrogen flow. After the reduction, the atmosphere was purged by pure nitrogen for $30 \mathrm{~min}$ and reoxidized by air to remove the possible adsorbed hydrocarbons and coke. In the isothermal redox experiment, the sample was heated to $600^{\circ} \mathrm{C}$ under the flow of nitrogen at a flow of $25 \mathrm{ml} / \mathrm{min}$. An ethylbenzene/nitrogen flow with an ethylbenzene partial pressure of $\sim 1 \%$ was introduced to the XRD cell as the ethylbenzene-TPR step. After the ethylbenzene-TPR step lasted for $30 \mathrm{~min}$, the cell was then purged by pure nitrogen for $18 \mathrm{~min}$. Thereafter, the atmosphere was changed to air tor reoxidize the reduced sample at the same flow rate. Two redox cycles were proceeded in the reactor. Nitrogen was used to purge the reaction system between two cycles. XRD scans were taken every 6 min.

XPS was used to analyze surface compositions and valence states of fresh, 3-min prereduced, 20-min reduced, 40-min deep-reduced, reoxidized, and long-term cycled catalysts. The reduced samples with different reduction time and cycled samples were obtained from the isothermal redox at $600^{\circ} \mathrm{C}$ at the condition as mentioned in the section of the catalytic evaluation. The reduced samples were transferred to a glove box filled with nitrogen atmosphere to avoid air exposure and sealed in sampling bottles before transporting to the XPS chamber. The sample powder was pressed onto a carbon tape and outgassed at $10^{-5}$ Torr for overnight before it was introduced into the ultrahigh-vacuum chamber for scanning. The XPS patterns were collected on a PHOIBIS 150 hemispherical energy analyzer (SPECS $\mathrm{GmbH})$ equipped with a non-monochromatic $\mathrm{Mg} \mathrm{Ka}$ excitation source $(1254 \mathrm{eV})$. The data were analyzed by the CasaXPS program (Casa Software Ltd, UK). The binding energy was calibrated to a C $1 s$ line at $284.6 \mathrm{eV}$. The surface compositions of $\mathrm{K}, \mathrm{Ca}, \mathrm{Fe}$, and $\mathrm{Mn}$ were calculated according to characteristic peak areas and their respective atomic sensitivity factors.

LEIS was conducted at the Surface Analysis Center at Lehigh University with an ION-TOF Qtac ${ }^{100}$ for surface compositional analysis and depth profiling. The samples tested for LEIS were fully oxidized $(\mathrm{Ca} / \mathrm{Mn})_{1-x} \mathrm{O} @ \mathrm{KFeO}_{2}$ and 20 -min reduced $(\mathrm{Ca} / \mathrm{Mn})_{1-x} \mathrm{O} @ \mathrm{KFeO}_{2}$ under ethylbenzene ODH operating scheme. The sample collection and storage scheme is the same as the abovementioned XPS section. The detection source was $3 \mathrm{keV} \mathrm{He}+\left(5 \times 10^{14} / \mathrm{cm}^{2} / \mathrm{cycle}, 1.5 \times 1.5 \mathrm{~mm}^{2}\right.$ raster). The sputtering source was $1.0 \mathrm{keV} \mathrm{Ar}+\left(1.0 \times 10^{15} / \mathrm{cm}^{2} / \mathrm{cycle}, 2 \times 2 \mathrm{~mm}^{2}\right.$ raster. Due to the similar atomic mass, $\mathrm{K}$ and $\mathrm{Ca}$ and $\mathrm{Mn}$ and $\mathrm{Fe}$ cannot be separated in LEIS analysis. Thus, $\mathrm{K}$ and $\mathrm{Ca}$ and $\mathrm{Mn}$ and $\mathrm{Fe}$ were lumped together in the surface compositional analysis.

Ethylbenzene TPSR with FTIR (TPSR-FTIR) spectroscopy was conducted using a Thermo Fisher Nicolet iS50 FTIR equipped with a DiffusIR sample chamber (Pike Technologies). The sample was first loaded into the in situ cell and purged with $\mathrm{Ar}$ at $100^{\circ} \mathrm{C}$ to desorb surface $\mathrm{CO}_{2}$. Ethylbenzene vapor was then introduced into the in situ cell at $100^{\circ} \mathrm{C}$ for $30 \mathrm{~min}$ for ethylbenzene surface adsorption, by flowing Ar through an ethylbenzene bubbler located at room temperature. Then, the ethylbenzene vapor flow was stopped, and the in situ cell was purged with $\mathrm{Ar}$ at $100^{\circ} \mathrm{C}$ for $30 \mathrm{~min}$. Afterwards, the in situ cell was raised from 100 to $600{ }^{\circ} \mathrm{C}$ and FTIR scans were taken at $100-600^{\circ} \mathrm{C}$. Isothermal FTIR was conducted at $500{ }^{\circ} \mathrm{C}$. The in situ cell was held at $500^{\circ} \mathrm{C}$ under Ar. Then, ethylbenzene vapor was introduced into the in situ cell by flowing $\mathrm{Ar}$ through an ethylbenzene bubbler located at room temperature. FTIR scans were taken every $2 \mathrm{~min}$.

Raman was conducted on the $(\mathrm{Ca} / \mathrm{Mn})_{1-x} \mathrm{O} @ \mathrm{KFeO}_{2}$ catalyst after 20 min ethylbenzene ODH. The instrument was a multiwavelength Raman system. The signal was collected via a customized ellipsoidal mirror and directed by a fiber optics bundle to the spectrograph stage of a triple Raman spectrometer (Acton Trivista 555 from Princeton Instruments). Edge filters (Semrock) were used in front of the ultraviolet-visible fiber optic bundle (Princeton Instruments) to block the laser irradiation. A 442-nm visible laser was used as the excitation beam, which is generated from a HeCd laser (Melles Griot). A ultraviolet-enhanced liquid $\mathrm{N}_{2}$ cooled CCD detector (Princeton Instrument) was employed for signal detection. Transmission electron microscopy with energy-dispersive $\mathrm{x}$-ray spectroscopy (TEM-EDX) was conducted with an aberration-corrected scanning transmission electron microscope-Thermo Fisher Titan 80-300. Mössbauer spectroscopy was conducted in Dalian Institute of Chemical Physics. ${ }^{57} \mathrm{Fe}$ Mössbauer spectra were collected at room temperature with a constant accelerations mode using ${ }^{57} \mathrm{Co} \gamma$ quantum source in the Rh matrix. All spectra were computer-fitted with a leastsquares fitting procedure to a Lorentzian shape. The isomer shifts were set with respect to $\alpha-\mathrm{Fe}$ at room temperature.

KIE and isotopic exchange experiments. KIEs were calculated as the ratio of normal ethylbenzene consumption rate to deuterium ethylbenzene consumption rate under identical redox-ODH conditions. The ODH experiments over redox catalysts were conducted separately using ethylbenzene and deuterium ethylbenzene. Typically, KIE was determined using lower conversion $(<20 \%)$. To achieve ethylbenzene conversions $<20 \%, 30 \mathrm{mg}$ of redox catalyst was loaded into a fixed bed quartz U-tube reactor and then the ethylbenzene/Ar (or deuterium ethylbenzene/Ar) mixture $(25 \mathrm{ml} / \mathrm{min})$ with an ethylbenzene partial pressure of $\sim 0.01 \mathrm{~atm}$ was introduced into the reactor, as described in Supplementary Fig. 1. The ethylbenzene ODH experiments was conducted in ethylbenzene/Ar in the range $300-600{ }^{\circ} \mathrm{C}$ at a rate of $10^{\circ} \mathrm{C} / \mathrm{min}$. Afterwards, the temperature was kept at $600^{\circ} \mathrm{C}$ for $20 \mathrm{~min}$ with the continuous ethylbenzene/Ar flow. Similarly, the deuterium ethylbenzene ODH experiments were conducted by using deuterium ethylbenzene/Ar mixture. The products were detected and quantified via either a downstream or an upstream QMS (MKS Cirrus II)

Isotopic exchange experiment over the redox catalyst was conducted in an isothermal ODH using co-feed of ethylbenzene and deuterium ethylbenzene to explore the styrene isotopes distribution. The same experimental setup in Supplementary Fig. 1 was used. To achieve an ethylbenzene conversion close to $100 \%, 0.5 \mathrm{~g}$ of redox catalyst was loaded into a fixed bed reactor. The bubbler was filled by the same volume of ethylbenzene and deuterium ethylbenzene to obtain an equal partial pressure. The $\mathrm{ODH}$ reaction was conducted at $600{ }^{\circ} \mathrm{C}$ with the continuous normal-deuterium ethylbenzene/Ar flow $(25 \mathrm{ml} / \mathrm{min})$ for $20 \mathrm{~min}$. The styrene products were detected and quantified via a downstream quadruple mass spectroscopy (QMS, MKS Cirrus II). Styrene and deuterated styrene were the main products with $m / z$ in the range $104-112$, corresponding to $\mathrm{C}_{8} \mathrm{H}_{8-x} \mathrm{D}_{x}(x=0,1,2$, $3,4,5,6,7,8)$, respectively. The styrene distributions were calculated on the basis of the relative proportion of the signals of $\mathrm{C}_{8} \mathrm{H}_{8-\mathrm{x}} \mathrm{D}_{\mathrm{x}}$ from mass spectroscopy since both the styrene and deuterium styrenes have very similar mass spectroscopy response factors.

DFT simulation. First-principles simulations were performed at the DFT level implemented by the Vienna ab initio simulation package. All-electron projector augmented wave model and Perdew-Burke-Ernzerhof functions were employed. A kinetic energy cutoff of $450 \mathrm{eV}$ was used for the plane-wave expansion of the electronic wave function. The force and energy convergence criterion was set to be $0.01 \mathrm{eV} / \AA$ and $10^{-5} \mathrm{eV}$, respectively. A Gaussian smearing of $0.1 \mathrm{eV}$ was applied for optimization. A $k$-point grid with a $4 \times 4 \times 2$ Gamma-centered mesh for pure $\mathrm{KFeO}_{2}$ unit cell and only Gamma mesh for all the surface slab models were chosen for sampling the first Brillouin zone. Due to the complexity of the $\mathrm{KFeO}_{2}$ surface structure, it is very difficult to accurately try each magnetic ordering. To make the calculations tractable, here we apply the ferromagnetic state for all the structures given that the tiny energy differences due to different magnetic ordering are negligible compared with ionic migration. The strong on site Coulomb interaction on the $d$-orbital electrons on the Fe sites was treated with the GGA + U approach. We adopted $U_{\text {eff }}=4 \mathrm{eV}$ for Hund's exchange interaction, which has been proved to give reasonable predictions of both geometric and electronic structures in previous works. The computed lattice constants of $\mathrm{KFeO}_{2}(a=5.68 \AA, b=11.38 \AA, c=16.07 \AA)$ match well with the experimental values $(a=5.61 \AA, b=11.21 \AA ⿻, c=15.26 \AA)$, showing the reliability of the computational settings ${ }^{1}$. The climbing image nudged elastic band method was applied for transition sate optimization. The adsorption energy of ethylbenzene on $\mathrm{KFeO}_{2}$ surface is computed with $E_{\mathrm{ads}}=E_{\mathrm{sur}}+E_{\mathrm{EB}}-E_{\text {sur-EB }}$, where $E_{\text {sur }}, E_{\mathrm{EB}}$, and $E_{\text {sur-EB }}$ are energies of $\mathrm{KFeO}_{2}$ surface model, ethylbenzene molecule, and the adsorbed configuration.

\section{Data availability}

The data that support the findings of this study are available from the corresponding author on reasonable request.

Received: 1 October 2020; Accepted: 25 January 2021; Published online: 26 February 2021 


\section{References}

1. Vaughan, B. A., Webster-Gardiner, M. S., Cundari, T. R. \& Gunnoe, T. B. A rhodium catalyst for single-step styrene production from benzene and ethylene. Science 348, 421-424 (2015).

2. Dimian, A. C. \& Bildea, C. S. Energy efficient styrene process: design and plantwide control. Ind. Eng. Chem. Res. 58, 4890-4905 (2019).

3. Cavani, F. \& Trifiro, F. Alternative processes for the production of styrene. Appl. Catal. Gen. 133, 219-239 (1995).

4. Kainthla, I., Bhanushali, J. T., Keri, R. S. \& Nagaraja, B. M. Activity studies of vanadium, iron, carbon and mixed oxides based catalysts for the oxidative dehydrogenation of ethylbenzene to styrene: a review. Catal. Sci. Technol. 5, 5062-5076 (2015).

5. Muhler, M. et al. The nature of the iron oxide-based catalyst for dehydrogenation of ethylbenzene to styrene: I. Solid-state chemistry and bulk characterization. J. Catal. 126, 339-360 (1990).

6. Hirano, T. Roles of potassium in potassium-promoted iron oxide catalyst for dehydrogenation of ethylbenzene. Appl. Catal. 26, 65-79 (1986).

7. Vasudevan, S., Rangaiah, G. P., Konda, N. V. S. N. M. \& Tay, W. H. Application and evaluation of three methodologies for plantwide control of the styrene monomer plant. Ind. Eng. Chem. Res. 48, 10941-10961 (2009).

8. Luyben, W. L. Design and control of the styrene process. Ind. Eng. Chem. Res. 50, 1231-1246 (2011).

9. Sivaranjani, K., Verma, A. \& Gopinath, S. C. Molecular oxygen-assisted oxidative dehydrogenation of ethylbenzene to styrene with nanocrystalline $\mathrm{Ti}_{1-x} \mathrm{~V}_{x} \mathrm{O}_{2}$. Green. Chem. 14, 461-471 (2012).

10. Guo, F. et al. Nanosheets for the oxidative dehydrogenation of ethylbenzene. Angew. Chem. 129, 8343-8347 (2017).

11. Keller, N. et al. The catalytic use of onion-like carbon materials for styrene synthesis by oxidative dehydrogenation of ethylbenzene. Angew. Chem. Int. Ed. 41, 1885-1888 (2002).

12. Pereira, M. F. R., Orfao, J. J. M. \& Figueiredo, J. L. Oxidative dehydrogenation of ethylbenzene on activated carbon catalysts. I. Influence of surface chemical groups. Appl. Catal. Gen. 184, 153-160 (1999).

13. Zhang, L. et al. Role of $\mathrm{CO}_{2}$ as a soft oxidant for dehydrogenation of ethylbenzene to styrene over a high-surface-area ceria catalyst. ACS Catal. 5, 6426-6435 (2015).

14. Bismillah Ansari, M. \& Park, S.-E. Carbon dioxide utilization as a soft oxidant and promoter in catalysis. Energy Environ. Sci. 5, 9419-9437 (2012).

15. Badstube, T., Papp, H., Dziembaj, R. \& Kustrowski, P. Screening of catalysts in the oxidative dehydrogenation of ethylbenzene with carbon dioxide. Appl. Catal. Gen. 204, 153-165 (2000).

16. Kainthla, I., Babu, G. V. R., Bhanushali, J. T., Rao, K. S. R. \& Nagaraja, B. M. Development of stable $\mathrm{MoO}_{3} / \mathrm{TiO}_{2}-\mathrm{Al}_{2} \mathrm{O}_{3}$ catalyst for oxidative dehydrogenation of ethylbenzene to styrene using $\mathrm{CO}_{2}$ as soft oxidant. J. $\mathrm{CO}_{2}$ Util. 18, 309-317 (2017).

17. Chang, J.-S. et al. Utilization of carbon dioxide as soft oxidant in the dehydrogenation of ethylbenzene over supported vanadium-antimony oxide catalysts. Green. Chem. 5, 587-590 (2003).

18. Saito, K., Okuda, K., Ikenaga, N., Miyake, T. \& Suzuki, T. Role of lattice oxygen of metal oxides in the dehydrogenation of ethylbenzene under a carbon dioxide atmosphere. J. Phys. Chem. A 114, 3845-3854 (2010).

19. Ohishi, Y. et al. Dehydrogenation of ethylbenzene with $\mathrm{CO}_{2}$ over Cr-MCM-41 catalyst. J. Mol. Catal. Chem. 230, 49-58 (2005).

20. Lau, Y. et al. Large scale in silico screening of materials for carbon capture through chemical looping. Energy Environ. Sci. 10, 818-831 (2017).

21. Bui, M. et al. Carbon capture and storage (CCS): the way forward. Energy Environ. Sci. 11, 1062-1176 (2018).

22. Hossain, M. M. \& de Lasa, H. I. Chemical-looping combustion (CLC) for inherent $\mathrm{CO}_{2}$ separations-a review. Chem. Eng. Sci. 63, 4433-4451 (2008).

23. Zeng, L., Cheng, Z., Fan, J. A., Fan, L.-S. \& Gong, J. Metal oxide redox chemistry for chemical looping processes. Nat. Rev. Chem. 2, 349-364 (2018).

24. Fan, L.-S., Zeng, L. \& Luo, S. Chemical-looping technology platform. AIChE J. 61, 2-22 (2015).

25. Sushkevich, V. L., Palagin, D., Ranocchiari, M. \& van Bokhoven, J. A. Selective anaerobic oxidation of methane enables direct synthesis of methanol. Science 356, 523-527 (2017).

26. Kang, Y. et al. Improving syngas selectivity of $\mathrm{Fe}_{2} \mathrm{O}_{3} / \mathrm{Al}_{2} \mathrm{O}_{3}$ with yttrium modification in chemical looping methane conversion. ACS Catal. 9 , 8373-8382 (2019).

27. Liu, Y. et al. Near $100 \%$ CO selectivity in nanoscaled iron-based oxygen carriers for chemical looping methane partial oxidation. Nat. Commun. 10, 1-6 (2019).

28. Bhavsar, S. \& Veser, G. Chemical looping beyond combustion: production of synthesis gas via chemical looping partial oxidation of methane. RSC Adv. 4, 47254-47267 (2014)
29. Cheng, Z. et al. C2 selectivity enhancement in chemical looping oxidative coupling of methane over a $\mathrm{Mg}-\mathrm{Mn}$ composite oxygen carrier by Li-doping-induced oxygen vacancies. ACS Energy Lett. 3, 1730-1736 (2018).

30. Muhich, C. L. et al. Efficient generation of $\mathrm{H} 2$ by splitting water with an isothermal redox cycle. Science 341, 540-542 (2013).

31. Jiang, Q. et al. Mixed conductive composites for 'low-temperature' thermochemical $\mathrm{CO}_{2}$ splitting and syngas generation. J. Mater. Chem. A 8 , 13173-13182 (2020)

32. Donat, F. \& Müller, C. R. $\mathrm{CO}_{2}$-free conversion of $\mathrm{CH} 4$ to syngas using chemical looping. Appl. Catal. B 278, 119328 (2020).

33. Maiti, D. et al. Earth abundant perovskite oxides for low temperature $\mathrm{CO}_{2}$ conversion. Energy Environ. Sci. 11, 648-659 (2018).

34. Metcalfe, I. S. et al. Overcoming chemical equilibrium limitations using a thermodynamically reversible chemical reactor. Nat. Chem. 11, 638-643 (2019).

35. Zhang, J., Haribal, V. \& Li, F. Perovskite nanocomposites as effective $\mathrm{CO}_{2}-$ splitting agents in a cyclic redox scheme. Sci. Adv. 3, el701184 (2017).

36. He, F. \& Li, F. Perovskite promoted iron oxide for hybrid water-splitting and syngas generation with exceptional conversion. Energy Environ. Sci. 8, 535-539 (2015).

37. Haribal, V. P. et al. Modified ceria for "low-temperature" $\mathrm{CO}_{2}$ utilization: a chemical looping route to exploit industrial waste heat. Adv. Energy Mater. 9, 1901963 (2019).

38. Dou, J. et al. A-and B-site codoped $\mathrm{SrFeO}_{3}$ oxygen sorbents for enhanced chemical looping air separation. ChemSusChem 13, 385-393 (2020).

39. Dou, J. et al. $\mathrm{Sr}_{1-\mathrm{X}} \mathrm{Ca}_{\mathrm{X}} \mathrm{Fe}_{1-\mathrm{Y}} \mathrm{CoyO}_{3-\delta}$ as facile and tunable oxygen sorbents for chemical looping air separation. J. Phys. Energy 2, 025007 (2020).

40. Vieten, J. et al. Materials design of perovskite solid solutions for thermochemical applications. Energy Environ. Sci. 12, 1369-1384 (2019).

41. Gao, Y. et al. A molten carbonate shell modified perovskite redox catalyst for anaerobic oxidative dehydrogenation of ethane. Sci. Adv. 6, eaaz9339 (2020).

42. Chen, S. et al. Modulating lattice oxygen in dual-functional Mo-V-O mixed oxides for chemical looping oxidative dehydrogenation. J. Am. Chem. Soc. 141, 18653-18657 (2019).

43. Neal, L. M., Haribal, V. P. \& Li, F. Intensified ethylene production via chemical looping through an exergetically efficient redox scheme. iScience 19 894-904 (2019).

44. Zhu, X., Donat, F., Imtiaz, Q., Müller, C. R. \& Li, F. Chemical looping beyond combustion-a perspective. Energy Environ. Sci. 13, 772-804 (2020).

45. Adanez, J., Abad, A., Garcia-Labiano, F., Gayan, P. \& Luis, F. Progress in chemical-looping combustion and reforming technologies. Prog. Energy Combust. Sci. 38, 215-282 (2012)

46. Gaillot, A.-C., Lanson, B. \& Drits, V. A. Structure of birnessite obtained from decomposition of permanganate under soft hydrothermal conditions. 1 . Chemical and structural evolution as a function of temperature. Chem. Mater. 17, 2959-2975 (2005).

47. Otero Arean, C. \& Stone Frank, S. Solid solution in the CaO-MnO system. J. Chem. Soc. Faraday Trans. 75, 2285-2294 (1979).

48. Muhler, M., Schlögl, R., Reller, A. \& Ertl, G. The nature of the active phase of the Fe/K-catalyst for dehydrogenation of ethylbenzene. Catal. Lett. 2, 201-210 (1989).

49. Merzlikin, S. V. et al. Anomalous surface compositions of stoichiometric mixed oxide compounds. Angew. Chem. Int. Ed. 49, 8037-8041 (2010).

50. Kuang, K. et al. Fire suppressing performance of superfine potassium bicarbonate powder. Fire Mater. 35, 353-366 (2011)

51. Legutko, P. et al. Strong enhancement of DeSoot activity of transition metal oxides by alkali doping: additive effects of potassium and nitric oxide. Top. Catal. 60, 162-170 (2017)

52. Fan, $\mathrm{H}$. et al. Ethylbenzene dehydrogenation to styrene with $\mathrm{CO}_{2}$ over $\mathrm{V}_{2} \mathrm{O}_{5}$ (001): a periodic density functional theory study. Chem. Eng. Sci. 135, 403-411 (2015).

53. Fan, H.-X. et al. Role of $\mathrm{CO}_{2}$ in the oxy-dehydrogenation of ethylbenzene to styrene on the $\mathrm{CeO}_{2}$ (111) surface. Appl. Surf. Sci. 427, 973-980 (2018)

54. Sharma, P., Dwivedi, R., Dixit, R., Batra, M. S. \& Prasad, R. A DFT study of oxidative dehydrogenation of ethyl benzene to styrene over zirconium vanadate catalyst. J. Comput. Methods Mol. Des. 4, 1-14 (2014).

55. Miyakoshi, A., Ueno, A. \& Ichikawa, M. XPS and TPD characterization of manganese-substituted iron-potassium oxide catalysts which are selective for dehydrogenation of ethylbenzene into styrene. Appl. Catal. Gen. 219, 249-258 (2001).

56. Baghalha, M. \& Ebrahimpour, O. Structural changes and surface activities of ethylbenzene dehydrogenation catalysts during deactivation. Appl. Catal. Gen. 326, 143-151 (2007).

57. Merte, L. R. Water-mediated proton hopping on an iron oxide surface. Science 336, 889-893 (2012). 
58. Skoufa, Z., Heracleous, E. \& Lemonidou, A. A. On ethane ODH mechanism and nature of active sites over $\mathrm{NiO}$-based catalysts via isotopic labeling and methanol sorption studies. J. Catal. 322, 118-129 (2015).

\section{Acknowledgements}

This work was supported by the US Department of Energy (RAPID Subaward DEEE0007888-05-6), the US National Science Foundation (Award No. CBET-1923468), and the Kenan Institute for Engineering, Technology and Science at NC State University. Z.B. and Z.W. were supported by the US Department of Energy, Office of Science, Office of Basic Energy Sciences, Chemical Sciences, Geosciences, and Biosciences Division, Catalysis Science Program. Part of the work including in situ IR and Raman was conducted at the Center for Nanophase Materials Sciences, which is a DOE Office of Science User Facility. TEM and in situ XRD were conducted in Analytical Instrumentation Facility (AIF) at North Carolina State University. LEIS was done at the operando facilities at Leigh University, under the help of Dr. Henry Luftman and Dr. Israel E. Wachs. Mössbauer spectroscopy was done at Dalian Institute of Chemical Physics, under the help of Dr. Chuande Huang and Dr. Xiaodong Wang.

\section{Author contributions}

X.Z. and Y.G. had an equal contribution in designing and conducting the redox-ODH experiments, interpreting experimental results, and writing the manuscript. X.W. conducted the DFT simulation and compiled the corresponding write-up. V.H. conducted the ASPEN Plus simulation and compiled the corresponding write-up. J.L. conducted redox-ODH experiments at high ethylbenzene vapor pressures. Z.B. and Z.W. conducted the Raman experiments for this work. L.M.N. and H.W. provided suggestions to the experiments. F.L. supervised this work and wrote the manuscript.

\section{Additional information}

Supplementary information The online version contains supplementary material available at https://doi.org/10.1038/s41467-021-21374-2.

Correspondence and requests for materials should be addressed to F.L.

Peer review information Nature Communications thanks Nkululeko E. Damoyi and the other, anonymous, reviewer(s) for their contribution to the peer review of this work. Peer reviewer reports are available.

Reprints and permission information is available at http://www.nature.com/reprints

Publisher's note Springer Nature remains neutral with regard to jurisdictional claims in published maps and institutional affiliations.

cc) (i)

Open Access This article is licensed under a Creative Commons Attribution 4.0 International License, which permits use, sharing, adaptation, distribution and reproduction in any medium or format, as long as you give appropriate credit to the original author(s) and the source, provide a link to the Creative Commons license, and indicate if changes were made. The images or other third party material in this article are included in the article's Creative Commons license, unless indicated otherwise in a credit line to the material. If material is not included in the article's Creative Commons license and your intended use is not permitted by statutory regulation or exceeds the permitted use, you will need to obtain permission directly from the copyright holder. To view a copy of this license, visit http://creativecommons.org/ licenses/by/4.0/.

(C) The Author(s) 2021

\section{Competing interests}

The authors declare no competing interests.
The Author(s) 2021 